\title{
Some Thoughts on the Influence of Culture on Translation in Literary Translation
}

\author{
Min Zhang \\ School of Foreign Languages, Northwest University, Xi'an, Shaanxi, 710127, China \\ zyzmm@hotmail.com
}

Keywords: Literary translation; Culture; Influence; Context

\begin{abstract}
Translation is a cultural activity, which is influenced by many social and cultural factors. Here we want to study the translator's dual cultural identity, the specific status and status of national literature, and the choice of translation strategies. Language is the carrier of culture, culture is the soil of language, and translation is the bridge of intercultural communication. Translation is fundamentally a cross - cultural communication problem. From the meaning of culture, the influence of cultural factors on the translator and the process of translation is discussed. With the deepening of understanding of the context, people have become more and more aware of the important role of context in translation. Literary translation is more complex than not literary translation, mainly involving a variety of cultural factors. In order to translate properly, the translator must understand all kinds of cultural factors in the source language and the target language, that is, the cultural context, otherwise it will cause the improper translation.
\end{abstract}

\section{Introduction}

Language and culture are inseparable. Language is an organic part of culture. It records the development history of human culture, reflects the progress of social civilization and progress, and is a tool for communication, dissemination, continuation and development of culture. Its status is extremely heavy. At the same time, language can not exist out of culture, and it always grows in a certain cultural background. Culture is the great environment of language activities, and all kinds of cultural factors must be embodied in language and language [1]. In the process of language activity, there is a brand of culture everywhere, and the trace of culture is seen. Luo Changpei, a famous linguist, said: "language is the crystallization of a national culture. The past culture of this nation is spread by it, and the future culture is also advancing by it." Since the late 1980s, cultural criticism and cultural studies have been rising in western academic circles [2]. A large number of scholars began to study translation problems from different cultural perspectives, and a new school of cultural translation emerged. People no longer regard translation as a static, pure language behaviour, and regard it as a process of communication in a specific social and cultural background. In the translation field, this is also known as the cultural turn of translation. This paper mainly discusses the influence of culture on translation in literary translation.

\section{The Meaning of Culture}

A Book of British anthropologist Taylor in 1871 published the "original culture" in the definition of culture is very representative: "culture is a complex whole which includes knowledge, belief, art, morals, law, custom and people as members of society and obtained all the abilities and habits". In Germany, in recent years along with the development of intercultural communication, HeinzGogring proposed in translation theory is widely accepted definition: "culture is everything one needs to know and grasp and feel, one can to judge people's behaviour is consistent with or against their social role; on the other hand, can let people act in line with social expectations -- if people do not want to bear the consequences of the violation of social behaviour". From the above definition can be found, the meaning of culture actually contains two levels: the external culture is through a variety of physical products showing people making, including buildings, clothing, food, supplies, tools, literature, folk tales, such as art and music and people act language, posture and 
customs; the internal culture is shown by people thinking activities, including values, morality, religion etc. Deng Yanchang pointed out that "culture includes all the products of human society." It includes not only material things such as cities, organizations, schools, but also non material things such as thought, habit, family pattern, language and so on. In a word, culture refers to the whole way of life in a society [3-4].

Translation as a cultural activity is influenced by social and cultural factors, such as: the translator's dual cultural identity, national literature status, the original language and culture and the position of the target culture relations, social politics, social ideology, literary tradition and literary norms, values, aesthetic psychology and patronage will have a significant impact on the translation of the text, the choice of translation strategies.

First of all, the translator as two text conversion agents must be proficient in the source language and the target language, with two kinds of culture, familiar with the author and the work of the social cultural background, understand the author's writing style and artistic point of view, the only way the translator can take accurate transfer the original connotation of the task. But even if the translator has fully possessed the above conditions, his translation activities will be limited by himself, so that different versions will show different styles because of different translators [5]. As a special reader of the original, the translator must forget his own cultural identity and integrate as far as possible into the social and cultural background of the original. On the other hand, with the cultural background of the translator, the mode of thinking will inevitably mark the brand of the national culture. Therefore, no matter how hard he used a dispassionate attitude to the interpretation of the original, the interpretation will be inevitably affected by the translator's cultural background, the translator vacuum never make yourself completely in an isolated and translated language culture in translation activities.

\section{The Influence of Culture on Translation}

Translation is the activity expressed by another language in another language by the translator. It is the semantic expression of the language and the interpretation of culture. Therefore, translation is a very active language and culture system composed of many elements. As a bridge to disseminate knowledge and culture, translation is inevitably influenced by culture. There are two main aspects of the influence of culture on Translation: one is the influence on the translator and the two is the influence on the translation activities. Culture can not only promote translation activities, but also influence and even restrict translation activities to some extent [6].

The Influence of Culture on Translators. Translation is the communication between the information and the cultural exchange between the languages. It can be found that in the process of text conversion, the translator is the key. His knowledge, experience, and living environment will play a role in this process. As the servant of the two masters, the choice of the translator is often unconsciously influenced by many cultural factors. Wang Dongfeng analyzed several aspects of it: Aesthetic interference, political interference and ethical intervention. Liu Yingkai pointed out that the self-centred view of Chinese culture has a significant influence on the translation of foreign words [7-8]. For the translator, from the point of view of cultural communication, the text of translation should be regarded as a part of the broad social and cultural background. The translator should recognize the cultural factors in the source text to translate the translation that is accepted by the reader. A successful translator should have the following qualities when dealing with the cultural factors in Translation: two cultures are well known; an expert on cultural understanding; flexible transformation of cultural orientation; high cross-cultural sensitivity; a level of cultural evaluation. 


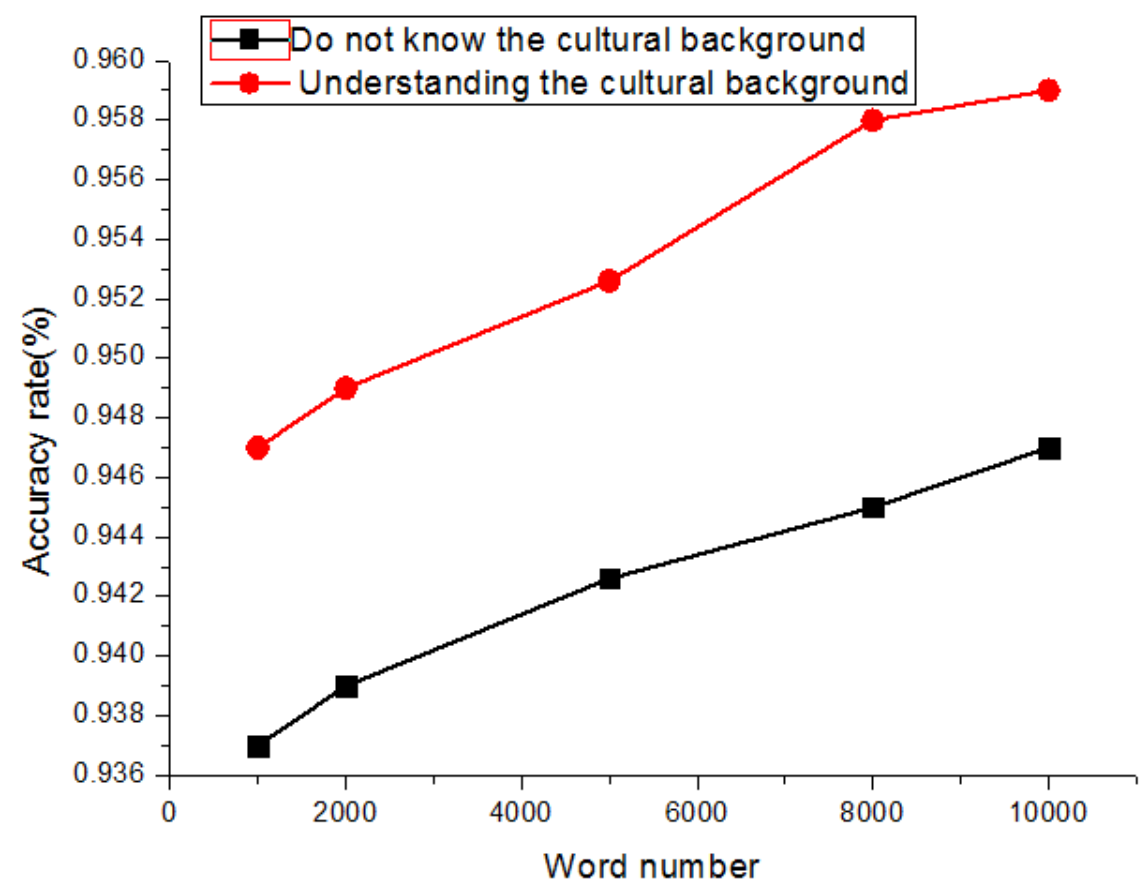

Figure 1. Finite The relationship between understanding of cultural background and the accuracy of translation

What means the translator takes in the process of translation will inevitably be influenced by the ideas of the people in a particular era. That is to say, the translator's view of translation is of an epochal nature. In the past, the translators believed that the vernacular language had no aesthetic sense, so it was often used in classical Chinese. This view, now, is obviously not acceptable. On the other hand, the influence of culture on the process of translation is also manifested in the change of translation in the development and change of culture [9]. All the translations are the results of the interpreters' interpretation of the original work, and the interpreters of the different translators may have different interpretations of the same original work. Therefore, the translation can never replace the original work completely, "coexistence" is the need of contending, and the "coexistence" also provides the reader with the possibility of choosing and judging. Fig. 1 shows the relationship between the translator's familiarity with the cultural background and the accuracy of the translation.

The Influence of Culture on Translation Activities. The influence of culture on translation activities is mainly reflected in two aspects: the scope and mode of national culture determining the translation activities, and the influence of culture on the process of translation.

(1) The national culture determines the scope and mode of translation activities. Translation as an activity, whether it can happen, how large the scale it is and what areas it involves are related to many aspects of the target language culture, especially with the conscious culture (or spiritual culture, conceptual culture). Among them, the degree of national psychological openness has great constraints on translation activities. The higher the openness of a nation is in the ideology, the more conducive to the development of the translation activities.

(2) The influence of culture on the process of translation.

On the one hand, the influence of culture on the process of translation is reflected in the translators' view of the translation of the times. Translation is the conversion of two languages. Understanding is of great importance, but the final result of translation is to be expressed. As a cultural individual, it is sometimes impossible to realize that we are affected by the culture. Therefore, in spite of the efforts to overcome the subjective factors in the process of translation, the result is still imprinted with the culture of the target language. Many problems in the theory of translation are related to "how to express" [10]. As the servant of the two masters, the choice of the translator is often unconsciously influenced by many cultural factors. When absorbing foreign cultures (including language and Culture), the translator's attitude is open or conservative, which 
has a great influence on the content and style of the translation. Translation is a transformation between different languages, so absorbing foreign language is not only necessary but also inevitable. Fig. 2 shows the influence of different cultural factors on literary translation.

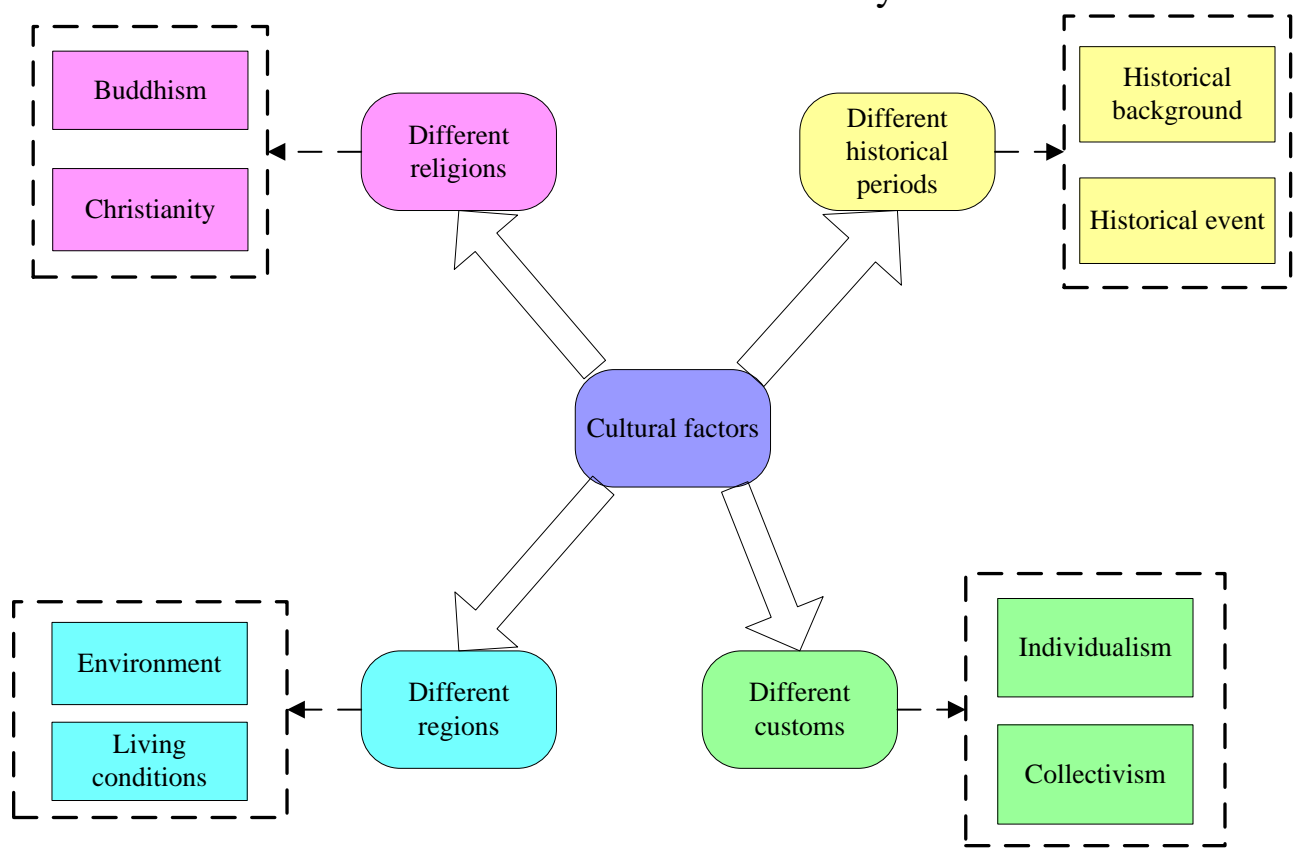

Figure 2. Finite Analysis of different cultural factors

Readers always look at their works from a historical perspective. They believe that the works of that era should be that characteristic, while the translation works are used to see in a realistic way. They always use the modern language and style to measure the past translations. The result is whether the old version will be fixed and the new version is sought. It is obvious that the function of the translation is timeliness, and the change of the translation is inevitable. Translation is the fact that there is limitation in the necessary retranslation of a certain work, especially when the old versions of the language and style does not meet the requirements of the times when. Cultural intervention in the process of translation can be reflected through the translation. "The translation of each period also revealed the language, the literary style of the publication, the demands of the readers and the general social and cultural situation. Through the comparison of these aspects, it can also be seen that the cultural development of a region or country is fast or slow, and the latter reflects the whole society."

\section{Summary}

Literary translation and cultural factors are inextricably linked, as $\mathrm{Mr}$. Xu Jun said in the translation process, due to the transfer of language, the original language has changed the original soil; the survival of the "cultural context must be deposited in another language culture re construction. And the resistance or test that this construction encountered may come from all levels of destination language: culture level, language level, reader's psychological level and reader's acceptance level. The language has changed, the cultural soil has changed, the reader has changed, and the translation opens a new space for the original work. It is in this sense that Derrida, a famous philosopher, believes that translation opens a new history of text in a new body and a new culture. It is in this sense that we can say that translation as the original work expands the space of life, and also gives the new value of the original work in this new open space. 


\section{References}

[1] Jiang Q, Quan X. Ideological impacts on literary translation - a descriptive study of translated literature in 1910-1931 and 1979-1999 in China[J]. Asia Pacific Translation \& Intercultural Studies, 2015, 2(3):174-186.

[2] Zhang Yue. Cultural imbalance and literary translation[J]. Journal of Jiamusi Vocational Institute, 2017.

[3] Chen J. On the Influence of Literature Translation from the Perspective of Ideology[J]. Overseas English, 2015.

[4] Lee, Hyungjin. Cultural Translation of Korean Literary Translation : Location of Cultural Translations of Korean Literature[J]. Journal of Translation Studies, 2016, 17.

[5] Flavia K P D. Literary Translation Between Albania and SpainA Cultural Bridge Between Two Countries[J]. 2017, 8(1):27.

[6] Hui-Hong L I. Feng Yidai's Literary Translation from the Perspective of Literary Communication[J]. Journal of Huaihua University, 2015.

[7] Branco S D O, Maia I N B, Branco S D O, et al. The inbetween place of literary translation: publishing demands and their implications in the formation of cultural identities[J]. Ilha Desterro, 2016, 69.

[8] Cadera S M, Walsh A. Literary Retranslation in Context[M]. 2017.

[9] Zhatkin D N, Milotaeva O S. D. E. Min's Creative Work in the History of the Russian Literary Translation of the XIXth Century[J]. Mediterranean Journal of Social Sciences, 2015, 6(3):219-225.

[10] Majcher A. Does the quality of interlingual translation influence the quality of the intersemiotic translation? On the English language film adaptations of S. Lem's The Futurological Congress and Solaris in the light of their translations into English[J]. Journal of Language \& Cultural Education, 2015, 3(3). 